\title{
Evaluation of LiDAR scanning for measurement of yield in perennial ryegrass
}

\author{
Richard M. GEORGE ${ }^{1}$, Brent A. BARRETT ${ }^{2}$ and Kioumars GHAMKHAR ${ }^{2 *}$ \\ ${ }^{1}$ PGG Wrightson Seeds, The Homestead, 10 Bisley Road, AgResearch Ruakura, Hamilton 3214, New Zealand \\ ${ }^{2}$ AgResearch Grasslands Research Centre, Private Bag 11008, Palmerston North, New Zealand \\ *corresponding author: kioumars.ghamkhar@agresearch.co.nz
}

\begin{abstract}
Improving pasture yields is a primary goal for plant breeders. However, measuring and selecting for yield is a major bottleneck in breeding, requiring methods that are laborious, destructive, and/or imprecise. A computerised scanner developed in Canterbury using LiDAR (light detection and ranging) technology was evaluated in the Waikato on perennial ryegrass pairedrow breeding plots. At eight timepoints, all plots were scanned prior to mechanical defoliation and recording of fresh weight $(\mathrm{FW})$ and dry matter (DM) yield on a random subset of plots. Yield data on $1206 \mathrm{FW}$ and 504 DM samples were compared with LiDAR scan results on a seasonal basis by regression. Winter, spring, summer and autumn correlation with $\mathrm{FW}$ were $\mathrm{R}^{2}=$ $0.81,0.92,0.94$ and 0.90 , respectively, and with DM yield $\mathrm{R}^{2}=0.87,0.73,0.87$ and 0.79 , respectively. These results indicate LiDAR estimation of DM yield was accurate within seasons for the paired-row breeding plots, although it was sensitive to large changes in dry matter content (\%) among seasons, which may require seasonal algorithms to correct for this variation if this technology is to be adopted. In conclusion, the scanner could be useful in removing a major bottleneck in perennial ryegrass breeding and may have application for agronomy and farm management in cases where precise non-destructive real-time estimation of DM yield are of value.
\end{abstract}

Keywords: dry matter yield, forage, LiDAR, plant breeding, perennial ryegrass, sensors

\section{Introduction}

Yield of perennial ryegrass is a complex trait with genetic, environment and management effects integrated by the plant and expressed dynamically over time (Conaghan et al. 2008; Parsons et al. 2011; Fè et al. 2015). Increasing seasonal DM yield is a major goal in pasture plant breeding, as it is the main economic trait in New Zealand pastures (Chapman et al. 2017). The rate of genetic improvement for a complex trait is influenced by the speed, accuracy and scale of the breeding strategy. Scale is generally limited by the number of breeding units that can be accurately evaluated at a low cost, thus limiting the rate of genetic gain. This has led to development of technology that may increase the speed and accuracy or lower the cost becoming a major goal for plant breeding in general (Furbank \& Tester 2011).

For seasonal DM yield of perennial ryegrass, breeders generally rely on 100 s to 10,000 s of plants to select among, making observations or collecting trait data for each plant, or plant progeny samples grown in a row or plot. In each regrowth cycle between defoliation events, breeders wait until the best plots in a field trial are at optimal regrowth, then estimate DM yield by visual assessment, or by mechanical defoliation followed by drying and weighing to measure DM yield empirically. Both methods have significant limitations in repeatability, accuracy, speed and/or cost. These limitations influence breeding strategy, constrain field trials, and limit the selection pressure applied for DM yield, and are ultimately a major bottleneck that limits the rate of genetic gain for seasonal DM yield in forage grass breeding.

Over the last decade, there has been a proliferation of 'phenomics'; the use of sensors and computer technology to measure plant traits in glasshouse and field settings. This has occurred for both plant breeding and agronomy, with progress and opportunities the subject of recent Australasian and global reviews (Gebremedhin et al. 2019; Roitsch et al. 2019).

Light detection and ranging (LiDAR), a sensorbased time of flight distance measurement method, and established technique in tree height measurement (Næsset 2002; Holmgren et al. 2003) and in-field forest characterisation (Harding et al. 2001; Lovell et al. 2003) is increasingly becoming useful in crop phenomics. It also maps soil and ground height (Reutebuch et al. 2003; Hodgson \& Bresnahan 2004). LiDAR is also being used as a component of pasture trait measurement systems (Schaefer \& Lamb 2016; Pittman \& Butler 2016) but only recently we used a LiDAR-based only system, which can measure forage DM yield in realtime (Ghamkhar et al. 2019). LiDAR both sends and receives laser signals. Unlike normal cameras, its scanners acquire depth and dispersal data (Fowler 2000). Ground-based types have shown accurate estimation of plant distribution (Saeys et al. 2009), DMY (Eitel et al. 2014) as well as biomass (Jimenez-Berni et al. 2018) in crops; among many promising observations from airborne types across different applications. In forages, 
LiDAR in perennial ryegrass has shown very accurate DM yield and biomass measurements in four different experiments in row plots with $\mathrm{R}^{2}>0.8$ for both traits (Ghamkhar et al. 2019).

Building on recent progress in Canterbury developing a mobile precision phenomics platform using LiDAR to measure seasonal DM in the field (Barrett et al. 2018; Ghamkhar et al. 2018), the aim of this study was to evaluate this platform for the accuracy of nondestructive, real-time estimation of FW and DM yield in a perennial ryegrass breeding trial in the Waikato.

\section{Materials \& Methods \\ Trial site \& management}

In spring 2017, 184 half-sib families from a perennial ryegrass breeding population were sown in an agronomic yield evaluation trial at Ruakura, Waikato, New Zealand (37०46'15.99'S, 175 18'25.99'E). A row-column experimental design with three replicates was used. Each replicate also contained six commercial breeding lines and 20 repeated checks. Each column consisted of 18 plots, and there were 35 rows ( 630 plots in total). Each plot consisted of a pair-row consisting of two adjacent, $2 \mathrm{~m}$ long rows sown on $15 \mathrm{~cm}$ centres with a cone seeder at $20 \mathrm{~kg} / \mathrm{ha}$. Spacings between outside rows of adjacent plots were $40 \mathrm{~cm}$ and columns were spaced $30 \mathrm{~cm}$ apart. A border row around the outside of the trial was included to reduce edge effects. The trial was rotationally grazed by a mob of $100-150$ sheep when $2200-3000 \mathrm{~kg} \mathrm{DM} / \mathrm{ha}$ were visually estimated to have accumulated in the top performing lines. (visual assessments were guided by dry matter information from prior harvests). Sheep were removed from the trial when post-grazing residuals were visually estimated to be $1200-1300 \mathrm{kgDM} / \mathrm{ha}$. Herbicides were applied when required to control broad leaf species and (bromoxynil, ioxynil, mecoprop-p and dicamba) tropical grass invasion (fenoxaprop-P-ethyl and mefenpyr-diethyl). Nitrogen fertiliser was applied as urea (46-0-0-0) at $200 \mathrm{~kg} \mathrm{~N} / \mathrm{ha} /$ year in small increments $(20-25 \mathrm{~kg} \mathrm{~N})$ following grazing.

\section{Yield and LiDAR data collection \& analysis}

LiDAR measurements were taken pre-grazing at eight time points between August 2018 and April 2019. Prior to each grazing, all plots were scanned using the M6 scanner platform. Development of the M6 platform is described elsewhere (Barrett et al. 2018). The scanner was set to a speed of $1 \mathrm{~km} / \mathrm{hr}$ and the front wheel width adjusted to straddle the inter-plot gap. The trial was scanned by driving the scanner down each row and back up the adjacent row in a serpentine pattern and data was saved as a .txt file at the end of each row.

In August 2018, post-LiDAR scan, a random subset of 324 plots were cut to $4 \mathrm{~cm}$ above ground level using a rotary lawn mower with the cut herbage weighed and recorded (fresh weight (FW)). At all subsequent harvests, only $20 \%$ of plots (126 plots) were cut and FW recorded. A further random subset of at least 50 samples per cut were dried at $80^{\circ} \mathrm{C}$ for at least 48 hours to obtain DM (g) and \%DM (DM/FW*100) to enable calculation of DM yield $(\mathrm{kg} / \mathrm{plot})$. The location of the 126 plots varied at each harvest, so no single plot was mechanically harvested more than once in five consecutive harvests. This ensured that breeding lines were exposed to as much ruminant grazing pressure as possible and helped mitigate any grazing-induced bias in yield or vegetative persistence among entries (this strategy was implemented after the August 2018 harvest). If substantial residual herbage remained after grazing, the entire trial was mown to a height of $4 \mathrm{~cm}$ to achieve a uniform residual. All harvested herbage was removed from the trial site.

LiDAR raw data were analysed using a software processing package that converts raw data to a unitless volumetric index (LiDAR volume, LV) via a developed algorithm by Ghamkhar et al. (2019). In the field, the LiDAR capture software parameters were set to: row length $=36 \mathrm{~m}$; segments per row $=$ 18 ; row spacing $=550 \mathrm{~mm}$; and cutting height $=40$ $\mathrm{mm}$. User-defined plot alignment was required from time-to-time to distinguish the start and end of plots. Results are presented by season and include data from multiple harvests. The number of harvests per season was dependent on growth rate. Yield and LV data were analysed in GenStat v18 including summary statistics, regression and comparison of slope among regressions.

\section{Results}

Yields varied considerably between seasons, with FW ranging from a mean of $0.23 \mathrm{~kg} / \mathrm{plot}$ in autumn to $0.74 \mathrm{~kg} /$ plot in summer (Table 1). Variation was also observed for DM yield, and DM \% on a seasonal basis, ranging from $21.7 \%$ in winter to $39.2 \%$ in autumn (Table 2).

Comparison of LV and FW data revealed strong correlations ranging from $\mathrm{R}^{2}=0.81$ in winter to $\mathrm{R}^{2}=$ 0.94 in summer (Figure 1, Table 1). A linear response was observed across all seasons for FW, although this deteriorated in summer and plateaued at very high FW values.

Correlations of $\mathrm{LV}$ and $\mathrm{DM}$ yield ranged from $\mathrm{R}^{2}=$ 0.73 in spring to 0.87 in summer (Figure 2, Table 2). Similar to FW, a linear response was observed within winter, spring and autumn for DM yield. The linear trend for summer broke down at very high levels of $\mathrm{DM}$, values well beyond the level of management parameters for herbage accumulation prior to grazing. 
The slope of the response was less $(\mathrm{P}<0.05)$ in autumn than the other seasons (Figure 2) which coincided with a higher DM\% (Table 2) in autumn than the other seasons.

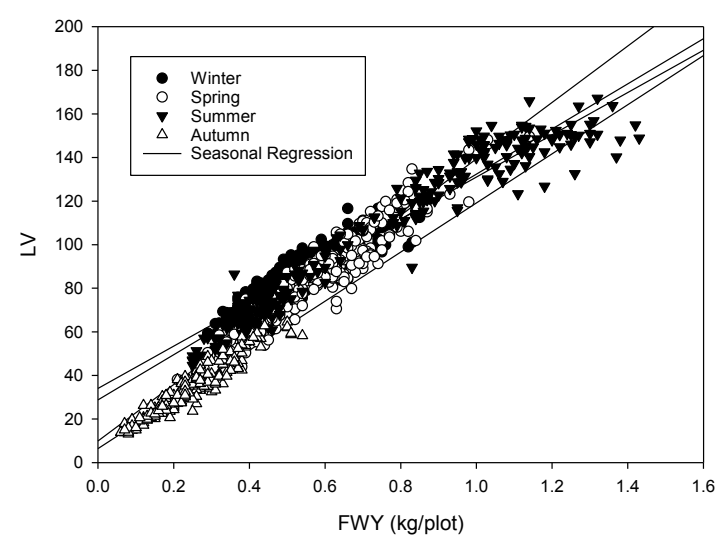

Figure 1 Correlation between harvested fresh weight yield (FWY) and the scanned LiDAR volume (LV) for each of 1206 paired-row plots randomly sampled and scanned at harvests between August 2018 and April 2019 in a perennial ryegrass breeding trial at Ruakura. Winter, spring, summer and autumn correlations were $\mathrm{R}^{2}=0.81,0.92,0.94$ and 0.90 , respectively

\section{Discussion}

These data suggest it is possible to rapidly and accurately assess yield in ryegrass paired-rows in the Waikato, at an accuracy comparable to that observed

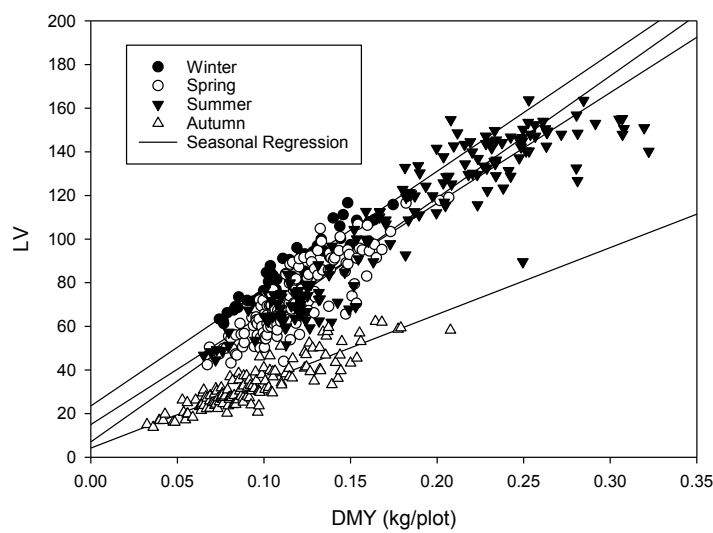

Figure 2 Correlation between harvested dry matter yield (DMY) and the scanned LiDAR volume (LV) for each of 504 paired-row plots randomly sampled and scanned at harvest between August 2018 and April 2019 in a perennial ryegrass breeding trial at Ruakura. Winter, spring, summer and autumn correlation with DMY were $\mathrm{R}^{2}=0.87,0.73,0.87$ and 0.79 , respectively.

Table 1 Seasonal summary of fresh weight (FW) and LiDAR volume (LV) data collected from 1206 paired-row plot harvests from the Ruakura breeding trial site between August 2018 and April 2019. $n=$ number of observations. $R^{2}=$ correlation coefficient.

\begin{tabular}{lccccccccccc}
\hline & & & \multicolumn{2}{c}{ Mean } & \multicolumn{2}{c}{ Standard deviation } & \multicolumn{2}{c}{ Minimum } & \multicolumn{2}{c}{ Maximum } \\
\cline { 5 - 11 } Season & $\mathbf{n}$ & $\mathbf{R}^{2}$ & FW (kg) & LV & FW (kg) & LV & FW (kg) & LV & FW (kg) & LV \\
\hline Winter & 324 & 0.81 & 0.52 & 84.78 & 0.11 & 11.92 & 0.29 & 56.96 & 0.87 & 121.67 \\
Spring & 378 & 0.92 & 0.54 & 80.36 & 0.15 & 20.13 & 0.21 & 38.06 & 1.14 & 149.61 \\
Summer & 252 & 0.94 & 0.74 & 105.20 & 0.33 & 35.11 & 0.25 & 44.57 & 1.43 & 167.18 \\
Autumn & 252 & 0.90 & 0.23 & 32.51 & 0.09 & 10.50 & 0.06 & 13.12 & 0.54 & 64.47 \\
Annual & 1206 & 0.92 & 0.51 & 76.74 & 0.25 & 32.33 & 0.06 & 13.12 & 1.43 & 167.18 \\
\hline
\end{tabular}

Table 2 Seasonal summary of DM yield and LiDAR volume (LV) data collected from 504 paired-row plot harvests from the Ruakura breeding trial site between August 2018 and April 2019. DM = Dry Matter percent, $n=$ number of observations, $\mathrm{R}^{2}=$ correlation coefficient.

\begin{tabular}{|c|c|c|c|c|c|c|c|c|c|c|c|c|}
\hline \multirow[b]{2}{*}{ Season } & \multirow[b]{2}{*}{$\mathbf{n}$} & \multirow[b]{2}{*}{$\mathbf{R}^{2}$} & \multicolumn{3}{|c|}{ Mean } & \multicolumn{3}{|c|}{ Standard deviation } & \multicolumn{2}{|c|}{ Minimum } & \multicolumn{2}{|c|}{ Maximum } \\
\hline & & & $\begin{array}{c}\text { DM } \\
\text { yield } \\
(\mathbf{k g})\end{array}$ & LV & $\begin{array}{l}\text { DM } \\
(\%)\end{array}$ & $\begin{array}{c}\text { DM } \\
\text { yield } \\
(\mathbf{k g})\end{array}$ & LV & $\begin{array}{l}\text { DM } \\
\text { (\%) }\end{array}$ & $\begin{array}{c}\text { DM } \\
\text { yield } \\
(\mathbf{k g})\end{array}$ & LV & $\begin{array}{c}\text { DM } \\
\text { yield } \\
\text { (kg) }\end{array}$ & LV \\
\hline Winter & 55 & 0.87 & 0.12 & 86.98 & 21.67 & 0.03 & 14.90 & 0.99 & 0.07 & 61.20 & 0.17 & 116.63 \\
\hline Spring & 144 & 0.73 & 0.12 & 72.68 & 25.17 & 0.03 & 16.63 & 1.74 & 0.07 & 42.39 & 0.21 & 119.08 \\
\hline Summer & 161 & 0.87 & 0.18 & 107.50 & 27.82 & 0.06 & 34.64 & 2.12 & 0.07 & 44.57 & 0.32 & 163.76 \\
\hline Autumn & 144 & 0.79 & 0.09 & 33.06 & 39.21 & 0.03 & 11.11 & 4.41 & 0.03 & 13.68 & 0.21 & 62.26 \\
\hline Annual & 504 & 0.79 & 0.13 & 74.05 & 28.47 & 0.06 & 37.11 & 2.32 & 0.03 & 13.68 & 0.32 & 163.76 \\
\hline
\end{tabular}


in Canterbury for single row plots (Barrett et al. 2018). Overall, the accuracy of the LiDAR in estimating both FW and DM yield compares favourably with prior reports for this LiDAR system (Barrett et al. 2018; Ghamkhar et al. 2018) and is a substantial advance on traditional methods (Smith et al. 2001).

The level of accuracy achieved here, ranging from 0.73 to 0.87 compares favourably with the $\mathrm{R}^{2}=0.76$ for pasture grass assessment using a more complex system relying on LiDAR augmented with an additional sensor providing normalised difference vegetation index data (Schaefer \& Lamb 2016). Ongoing improvements in the accuracy of the LiDAR scans may be achievable through factoring-in field trial format, germplasm characteristics, and continued algorithm improvements among other factors.

Plant breeders using visual assessment for DM yield typically have a varying degree of accuracy ranging from $\mathrm{R}^{2}=0.23$ to 0.75 for breeding rows and 0.16 to 0.85 for plots (Smith et al. 2001), and also vary among breeders, suggesting LiDAR scanning offers a substantial improvement in the quality of data available to support breeder decision making, which can be acquired at a speed similar to or above that achieved when collecting data by visual assessment.

The significant interaction of season by LV for DM yield prediction (Figure 2) suggests there is opportunity to further improved accuracy with the modification of algorithms for seasonal and/or regional conditions, or to incorporate a $\mathrm{DM} \%$ sensor as an additional data source. The impact of changes in $\mathrm{DM} \%$ may also have implications for measuring among differing populations of ryegrass and different species, including those differing in ploidy.

The high levels of accuracy within season suggest there may be potential to undertake repeated scanning during regrowth phases to monitor accumulation of dry matter over time. This could lead to assessment of growth rate on a weekly or even daily basis as a trait of interest in pasture grass breeding. The LiDAR sensor and its high level of accuracy may also create possibilities for agronomy and farm management applications where accurate, real-time and nondestructive assessment of pasture mass is of value. The technology may have applications in agronomy and pasture management and may be improved through use of seasonal or other context specific algorithms.

\section{Conclusion}

Use of mobile, non-destructive LiDAR scanning in the field to acquire dry matter yield data in trials evaluating perennial ryegrass breeding lines is further validated by this research, enabling levels of scale, accuracy and efficiency previously unattainable in forage plant breeding. This offers a substantial improvement on current practice, and addresses a major, longstanding bottleneck in data collection for the major economic trait (i.e. yield) in forage plant breeding.

\section{ACKNOWLEDGEMENTS}

We acknowledge technical support from Brian Maw and Matt Francis of PGG Wrightsons Seeds for field data collection, and the LiDAR system development and support contributions from Drs Kenji Irie and Michael Hagedorn of Redfern Solutions. The research to the develop the LiDAR scanning system was funded by Pastoral Genomics, a joint venture cofunded by DairyNZ, Beef + Lamb New Zealand, Dairy Australia, AgResearch Ltd, New Zealand Agriseeds Ltd, Grasslands Innovation Ltd, and the Ministry of Business, Innovation and Employment (New Zealand).

\section{REFERENCES}

Barrett BA, Faville MJ, Ghamkhar K, Carena MJ. 2018. Developing new tools for pasture plant breeding. Journal of New Zealand Grasslands 80: 255-261.

Chapman DF, Bryant JR, Olayemi ME, Edwards GR, Thorrold BS, McMillan WH, Kerr GA, Judson G, Cookson T, Moorhead A, Norriss M. 2017. An economically based evaluation index for perennial and short-term ryegrasses in New Zealand dairy farm systems. Grass and Forage Science 72: 1-21.

Conaghan P, Casler MD, McGilloway DA, O'Kiely P, Dowley LJ. 2008. Genotype x environment interactions for herbage yield of perennial ryegrass sward plots in Ireland. Grass and Forage Science 63: 107-120.

Eitel JU, Magney TS, Vierling LA, Brown TT, Huggins DR. 2014. LiDAR based biomass and crop nitrogen estimates for rapid, non-destructive assessment of wheat nitrogen status. Field Crops Research 159: 21-32.

Fè D, Pedersen MG, Jensen CS, Jensen J. 2015. Genetic and Environmental variation in a commercial breeding program of perennial ryegrass. Crop Science 55: 631-640.

Fowler RA. 2000. The lowdown on LIDAR. Earth Observation Magazine 9: 5.

Furbank RT, Tester M. 2011. Phenomics - technologies to relieve the phenotyping bottleneck. Trends in Plant Science 16: 635-644.

Gebremedhin A, Badenhorst PE, Wang J, Spangenberg GC, Smith KF. 2019. prospects for measurement of dry matter yield in forage breeding programs using sensor technologies. Agronomy 9: 65.

Ghamkhar K, Irie K, Hagedorn M, Hsiao J, Fourie J, Gebbie S, Flay C, Barrett B, Stewart A, Werner A. 2018. Using LIDAR for forage yield measurement of perennial ryegrass (Lolium perenne L.) field plots. Breeding Grasses and Protein Crops in the Era of 
Genomics, pp. 203-208. Springer International Publishing.

Ghamkhar K, Irie K, Hagedorn M, Hsiao J, Fourie J, Gebbie S, Hoyos-Villegas V, George R, Stewart A, Inch C. 2019. Real-time, non-destructive and infield foliage yield and growth rate measurement in perennial ryegrass (Lolium perenne L.). Plant Methods 15: 72.

Harding D, Lefsky M, Parker G, Blair J. 2001. Laser altimeter canopy height profiles: Methods and validation for closed-canopy, broadleaf forests. Remote Sensing of Environment 76: 283-297.

Hodgson ME, Bresnahan P. 2004. Accuracy of airborne lidar-derived elevation. Photogrammetric Engineering \& Remote Sensing 70: 331-339.

Holmgren J, Nilsson M, Olsson H. 2003. Estimation of tree height and stem volume on plots using airborne laser scanning. Forest Science 49: 419-428.

Jimenez-Berni JA, Deery DM, Rozas-Larraondo P, Condon ATG, Rebetzke GJ, James RA, Bovill WD, Furbank RT, Sirault XR. 2018. High throughput determination of plant height, ground cover, and above-ground biomass in wheat with LiDAR. Frontiers in Plant Science 9: 237.

Lovell J, Jupp DL, Culvenor D, Coops N. 2003. Using airborne and ground-based ranging lidar to measure canopy structure in Australian forests. Canadian Journal of Remote Sensing 29: 607-622.

Næsset E. 2002. Predicting forest stand characteristics with airborne scanning laser using a practical twostage procedure and field data. Remote Sensing of Environment 80: 88-99.
Parsons AJ, Edwards GR, Newton PCD, Chapman DF, Caradus JR, Rasmussen S, Rowarth JS. 2011. Past lessons and future prospects: Plant breeding for yield and persistence in cool-temperate pastures. Grass and Forage Science 66: 153-172.

Pittman J, Butler T. Noble Research Institute LLC assignee 2016. Forage biomass estimation devices, systems, and methods. US Patent: US20160084635A1.

Reutebuch SE, McGaughey RJ, Andersen H-E, Carson WW. 2003. Accuracy of a high-resolution lidar terrain model under a conifer forest canopy. Canadian Journal of Remote Sensing 29: 527-535.

Roitsch T, Cabrera-Bosquet L, Fournier A, Ghamkhar K, Jiménez-Berni J, Pinto F, Ober ES. 2019 Review: New sensors and data-driven approaches-A path to next generation phenomics. Plant Science 282: 2-10.

Saeys W, Lenaerts B, Craessaerts G, De Baerdemaeker J. 2009. Estimation of the crop density of small grains using LiDAR sensors. Biosystems Engineering 102: 22-30.

Schaefer MT, Lamb DW. 2016. A combination of plant NDVI and LiDAR measurements improve the estimation of pasture biomass in tall fescue (Festuca arundinacea var. Fletcher). Remote Sensing 8: 109.

Smith KF, Tasneem M, Kearney GA, Reed KFM, Leonforte A. 2001. Evaluation of herbage yield in a forage grass breeding program: comparison of visual rating versus measurement in single-row plots or swards. Australian Journal of Experimental Agriculture 41: 1161-1166. 
